\title{
Peribulbar Block with Akinesia: How to do it?
}

\author{
Martins P., Amorim J., Carvalho A.P., Guerreiro L., Carneiro J., Resende A.
}

Centro Hospitalar Lisboa Norte

\section{Background and Goal of Study}

Peribulbar Block is a safe and easily performed regional anaesthetic tecnique. This technique consists of a double injection of local anesthetic: one through the conjunctiva or lower eyelid between the lateral $1 / 3$ and the medial $2 / 3$ of the lower orbital margin, and other in the upper eyelid between the medial $1 / 3$ and the lateral $2 / 3$, close to the supraorbital notch. Some factors may influence the levels of akinesia in Peribulbar Block, namely the volume of the local anaesthetic injected. On the other hand, large volumes may affect intra-ocular pressure.

The goal of our study is to compare akinesia after Peribulbar Block with the volume of local anaesthetic, number and the site of injection and complications.

\section{Materials and Methods}

A prospective observational study was performed between May and October 2016. Peribulbar Block was performed with a $22 \mathrm{~mm}$ needle and $1 \%$ ropivacaine or $1 \%$ ropivacaine $+2 \%$ lidocaine with injection site at inferotemporal (IT), superonasal (SN), superotemporal (ST) and/or lacrimal caruncle (LC). A pressure of 30 $\mathrm{mmHg}$ was applied for 5-10 min and akinesia of each rectus muscle was evaluated 15 minutes after injection as "0 - Total", "1 - Partial" and "2 - No akinesia".

\section{Results and Discussion}

\begin{tabular}{|c|c|}
\hline \multicolumn{2}{|l|}{ PATIENT DATA } \\
\hline Study population (n) & 67 \\
\hline Mean age (years) & 72.52 \\
\hline Male sex (\%) & 50,7 \\
\hline ASA 2 (\%) & 68.7 \\
\hline ASA $3(\%)$ & 29,9 \\
\hline ASA $4(\%)$ & 1.5 \\
\hline \multicolumn{2}{|l|}{ PROCEDURE DATA } \\
\hline Vitrectomy (\%) & 14,9 \\
\hline $\begin{array}{l}\text { Phacoemulsification with intraocular lens } \\
\text { implantation (\%) }\end{array}$ & 76.1 \\
\hline $\begin{array}{l}\text { Vitrectomy + Phacoemulsification with } \\
\text { intraocular lens implantation (\%) }\end{array}$ & 3 \\
\hline Trabulectomy (\%) & 4,5 \\
\hline Ahmed valve revision (\%) & 1,5 \\
\hline
\end{tabular}

\begin{tabular}{|c|c|c|}
\hline \multicolumn{3}{|c|}{ PERIBULBAR BLOCK PERFORMANCE } \\
\hline \multicolumn{2}{|l|}{ Mean injections ( $\mathrm{n}$ ) } & 2.13 \\
\hline \multicolumn{2}{|c|}{ Superonasal (SN) mean volume $(\mathrm{mL})$} & 1,79 \\
\hline \multicolumn{2}{|c|}{ Inferotemporal (IT)mean volume (mL) } & 3,31 \\
\hline \multicolumn{2}{|c|}{ Lacrimal caruncle $(\mathrm{LC})$ mean volume $(\mathrm{mL})$} & 1,02 \\
\hline \multicolumn{2}{|c|}{ Superotemporal (ST) mean volume $(\mathrm{mL})$} & 0,75 \\
\hline \multicolumn{2}{|c|}{ Total mean volume $(\mathrm{mL})$} & 5,23 \\
\hline \multicolumn{3}{|c|}{ PERIBULBAR BLOCK RESULTS } \\
\hline \multirow{3}{*}{ Internal Akinesia (\%) } & 0 & 43,3 \\
\hline & 1 & 37,3 \\
\hline & 2 & 19,4 \\
\hline \multirow{3}{*}{ External Akinesia (\%) } & 0 & 38,8 \\
\hline & 1 & 43,3 \\
\hline & 2 & 17,9 \\
\hline \multirow{3}{*}{ Inferior Akinesia (\%) } & 0 & 56,7 \\
\hline & 1 & 31,3 \\
\hline & 2 & 11,9 \\
\hline \multirow{3}{*}{ Superior Akinesia (\%) } & 0 & 56,7 \\
\hline & 1 & 23,4 \\
\hline & 2 & 14,9 \\
\hline \multirow{3}{*}{ Total Quadrants Akinesia (\%) } & 0 & 23,9 \\
\hline & 1 & 68,6 \\
\hline & 2 & 7,5 \\
\hline
\end{tabular}

With the univariate analysis we verify that:

- IT volume was statistically significant ( $p$ 0.006) to superior akinesia

- IT volume ( 0.0001 ) and Total Volume ( $p$ 0.002) were statistically significant to external akinesia.

- Total Volume ( $p$ 0.004), number of injections ( $p$ 0.001) and SN volume ( $p$ 0.003) had statistical significance to the type of procedure

- There were no block-related complications.

\section{Conclusion(s):}

Our results show that the IT volume is important for superior and external akinesia and the Total Volume for external akinesia. About the type of procedure, the SN volume, the Total Volume and the number of injections affect the degree of akinesia. Multicenter studies with larger population and alternative techniques of Peribulbar Block are necessary to study how to improve the degree of akinesia. 